\title{
Surgical wayfinding and navigation processes in the human body
}

\author{
Thomas Stüdeli
}

(C) The Author(s) 2009. This article is published with open access at Springerlink.com

\section{Introduction}

During minimally invasive therapies (MITs) ${ }^{1}$, surgeons and interventionists rely on medical images as cartographic overviews over the working and navigation area in the patient's body.

MITs are reported as highly demanding for the surgeon's fine motor skills as well as for his cognitive capacities (Berguer 1999). Buess (2008) reports that many surgeons only master know-how for simple MITs and points out that different skill are needed for MITs than for open surgical procedures. MITs are characterized by limited access to the working area and thus also by limited and indirect spatial information. Cognitive load of the surgeon arises from the need not only to maintain spatial awareness but also to make correct decisions and solve problems. Cao and Milgram (2000) could show that the abdominal surgeons use considerable cognitive spatial capacities to maintain spatial awareness in the inner space of the anatomical cavity while operating in the colon with the help of an endoscopic video (colonoscopy). Dominguez (2001) could show differences in decision making and problem solving of experienced surgeons and surgeons in training and highlights their importance for surgical competency and excellence.

In order to reduce surgeons and interventionists cognitive workload during MITs, considerable amount of effort

T. Stüdeli $(\bowtie)$

Faculty of Industrial Design Engineering,

Delft University of Technology, Landbergstraat 15,

2628 CE Delft, The Netherlands

e-mail: t.p.studeli@ tudelft.nl

T. Stüdeli

Ergonomics and Product Design, Thomas Stüdeli,

Breitenacherweg 3, 2544 Bettlach, Switzerland is actually undertaken in the development of surgical information and navigation systems. In order to design intuitive tools that support medical experts in their time critical wayfinding and navigation tasks (in a working environment with high risks), a deeper understanding of safe and effective navigation and wayfinding strategies is mandatory. The development process of surgical information and navigation systems and their user interfaces could be substantially supported with a plain model that makes the complex information need-spatial-orientational as well as safety-strategical-comprehensible for designers and engineers.

In earlier work (within ARISER network), a plain model has been introduced based on the observed similarities in navigation strategies of surgeons (Stüdeli et al. 2007) and classical maritime navigators (Bowditch 1995, p. 371ff). Both experts rely on prudent navigation strategies which are described in the model as iterative and multifactor problem solving and quality control cycles (Stüdeli 2008, 2009). This model has been evaluated positively by four surgeons from different fields (abdominal, cardiac and pelvic surgery). One of the remaining questions was how to incorporate the prominent role of spatial mental models in surgery (e.g. Cao and Milgram 2000).

The here presented research describes the analysis of ethnographic data to link the "iterative and multifactor problem solving and quality control cycles" with the five elements of mental models of Lynch (1960).

\footnotetext{
${ }^{1}$ MIT is used in this paper as an umbrella term for all therapies aiming to minimize incisions and trauma to the patient including surgical (e.g., laparoscopic surgery, endoscopic surgery and keyhole surgery) and non-surgical approaches (e.g., intervention radiology). Other contending acronym-based alternatives are minimally invasive surgery (MIS) or minimal access surgery (MAS).
} 
Table 1 Spatial information need for surgical action-intra-operative navigation and wayfinding process

\begin{tabular}{|c|c|c|c|}
\hline $\begin{array}{l}\text { Anatomical } \\
\text { procedures }(n=2)\end{array}$ & Mental model & $\begin{array}{c}\text { Visual } \\
(\text { direct / indirect) }\end{array}$ & Haptic \\
\hline Node & $* * *$ & (i) $* * *$ & $* *$ \\
\hline Path & $* * *$ & (i) $* *$ & $* * *$ \\
\hline District & $* * *$ & (i) $* *$ & $* *$ \\
\hline Landmark & $* * *$ & \multirow{2}{*}{$(\mathrm{i}) * *$} & \multirow[b]{2}{*}{$* *$} \\
\hline Edge & $* *$ & & \\
\hline \multicolumn{4}{|l|}{$\begin{array}{l}\text { Unanatomical } \\
\text { procedures }(n=2)\end{array}$} \\
\hline Node & $* * *$ & $(i)^{* *}$ & $*$ \\
\hline Path & $* * *$ & $(i)^{* *}$ & - \\
\hline District & $* * *$ & $(\mathrm{~d}) * * /(\mathrm{i}) *$ & $* *$ \\
\hline Landmark & $* * *$ & $(\mathrm{~d}) * * /(\mathrm{i}) * *$ & \\
\hline Edge & $* *$ & (d)**/(i)* & $* *$ \\
\hline
\end{tabular}

*** Highly relevant $(>80 \%, 5$ out of 6 , found in interview, sketch, and verbalization). **Relevant ( $>50 \%, 3-4$ out of 6$)$. *Minor importance $(>15 \%$, minimal 1 out of 6$)$

\section{Methods}

The evaluation is based on a series of 26 structured interviews with surgeons and interventionists (subjects) and subsequent intra-operative observations of MITs (Stüdeli 2008).

\section{Structured interviews}

Each subject went through an initial interview about the therapy, general type of difficulties encountered, and strategies used for successful navigation. During the interview, the subjects were asked to draw their working area on a paper (sketch) by hand. The interviews were transcribed during the interview or directly afterwards.

Intra-operative observations

After the initial interviews, observation of three separate surgeries or interventions were conducted with each subject. During the operations the subjects were encouraged to speak aloud everything that he/she was thinking and doing. A scene camera was placed in the room to record the workflow and all verbalising for subsequent transcription and analysis.

\section{Analysis}

Interview data and sketches have been evaluated with an evaluation matrix that included spatial-orientational variables [(node, path, district, landmark, edge (Lynch 1960, p. 145)], safety-strategical variables (hazards, degree of accuracy and special attention), and information source (direct view, indirect view, haptic and mental model) (Table 1).

So far four interviews and subsequent observations of MITs have been analysed, two anatomical (catheter placements) and two unanatomical procedures (needle placements).

\section{Results}

Observation and interview data show the followings: when surgeons and interventionists are 'in action' their main information source is their spatial mental models of the patient's body (Table 1). The subjects often take all available information visual and haptic, combine them and use the combined information to check or reassure their findings.

The reason for the dominance of indirect view in the visual information is that both therapies (needle and catheter placement) heavily rely on imaging technology (indirect views) like almost all MITs. The only direct view the operator has in the needle placement is for the defining of the puncture place of the needle, and even there he retrieves all available haptic information (palpation). For haptic information, landmarks and edges (not possible to pass like bones) were treated equivalent by all subjects.

Whereas during a period of flow of work the spatial information is almost constantly updated with visual and haptic information from the workspace, the wayfinding process (safety, strategy) is less dynamic (Fig. 1). There

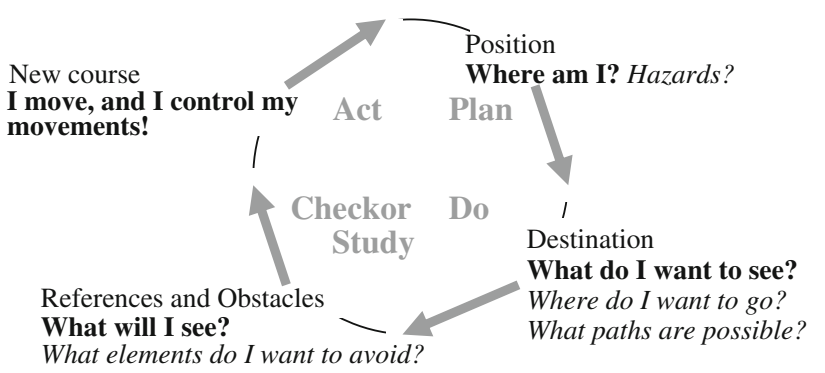

Fig. 1 The model shows two connected cycles (bold navigation, italic wayfinding). A cycle where strategic and safety related problems are solved (wayfinding aspects) and a cycle where the location and orientation aspects (navigational aspects) are controlled (adapted from Stüdeli 2009) 
the information need arises mainly at certain decision points (hazards, high accuracy and special attention). Then the activated wayfinding process is highly iterative and influenced by risk assessments to secure safety of the patient and to control further action (interwoven with navigation process).

\section{Discussion}

The plain model displayed in Fig. 1 indicates that medical wayfinders live in two worlds: the world in which the necessary surgical actions and navigation processes take place and the world where the patient health is kept under surveillance and safety decision are made. The wayfinder aims to coordinate as elegant as possible those two cognitive processes.

Even spatially rather simple approaches (work in one direction, determination of penetration depth and/or deviation angle) such as catheter placements or image-guided percutaneous needle placement are demanding in various aspects and a challenge for surgical education. Poon et al. (2004), e.g., report flat learning curves for percutaneous needle placement. The human body as a navigation environment has some specialties and actual surgical navigation systems do not cover the natural human navigation process sufficiently (Stüdeli 2008).

The here presented work is a first step towards an overall ontology of surgical wayfinding and navigation processes during MITs. The long-term aim is to understand and describe safe and effective surgical navigation processes and to make this knowledge accessible in a format that can be used beneficially for further developments of supportive technology for MITs. This high aim demands an approach across conventional disciplines.

Results show the importance of the spatial mental model of the medical experts during needle and catheter placements, they support the finding of previous work on examination of the large colon (Colonoscopy, Cao and Milgram 2000) as well as for gallbladder removal (Cholecystectomy; Dominguez 1997, 2001).

This paper outlines a theoretical phenomenology/cognitive model for describing prudent navigation and wayfinding processes. The model fits to the classical maritime navigation process (Bowditch 1995, p. 371ff) and the iterative problem solving and quality control process (Shewhart 1939). Additionally, it links to the five spatial mental elements of Lynch (1960). The model has been evaluated in four unstructured interviews with surgeons from different fields (two abdominal surgeons, a heart surgery and gynecologist). The feedback is positive. The aim is now to test more in detail and more concrete for specific navigation tasks. First, experimental evaluations of the efficacy of the model are actually taken place for the case of percutaneous needle placements in to the liver.

Acknowledgment The author would like to express his appreciation of the surgeons and interventionists who donated their time to share their expertise. All conducted observations and interviews comply with the current laws of the country in which they were performed.

Open Access This article is distributed under the terms of the Creative Commons Attribution Noncommercial License which permits any noncommercial use, distribution, and reproduction in any medium, provided the original author(s) and source are credited.

\section{References}

Berguer R (1999) Surgery and ergonomics. Arch Surg. doi: 10.1001/archsurg.134.9.1011

Bowditch NLLD (1995) The American Practical Navigator. http://www.irbs.com/bowditch/

Buess GF (2008) Natural orifice transluminal endoscopic surgery (NOTES). Minimally invasive therapy and allied technologies. doi:10.1080/13645700802528082

Cao CGL, Milgram P (2000) Disorientation in minimal access surgery: a case study. Proceedings of the XIVth Triennial Congress of the International Ergonomics Association and 44th Annual Meeting of the Human Factors and Ergonomics Association, 'Ergonomics for the New Millennium', pp 169-172

Dominguez CO (1997) First, do no harm: expertise and metacognition in laparoscopic surgery. Psychology Wright State University, Dayton

Dominguez CO (2001) Expertise and metacognition in laparoscopic surgery: a field study. Proceedings of the Human Factors and Ergonomics Society, pp 1298-1302

Lynch K (1960) Image of the city. MIT Press. London. ISBN 0262 620014

Poon RT, Kelvin K, Lam CM, Ai V, Yuen J, Fan ST, Wong J (2004) Learning curve for radiofrequency ablation of liver tumorsprospective analysis of initial 100 patients in a tertiary institution. Ann Surg 239(4):441-449

Shewhart WA (1939) Statistical method from the viewpoint of quality control. Dover, New York. ISBN 0-486-65232-7

Stüdeli T (2008) Surgical navigation during minimally invasive procedures. In: Casciaro S, Samset E (eds) Minimally invasive technologies and nanosystems for diagnosis and therapies. Lupiensis Biomedical Publications, Lecce, Italy, pp 177-186. ISBN 978-88-902880-2-9

Stüdeli T (2009) Kevin A. Lynchs Elemente mentaler Karten im Zeitalter Globaler Positionsbestimmungssysteme, Digitaler Karten und Navigationssysteme [Kevin A. Lynchs Elements of Mental Maps in Times of Global Positioning Systems, Digital maps and Navigation Systems], In: Arbeit, Beschäftigungsfähigkeit und Produktivität im 21. Jahrhundert, 55. Arbeitswissenschaftlichen Kongress der Gesellschaft für Arbeitswissenschaften e.V., Dortmund vom 4. bis 6. März 2008 an der Technischen Universität Dortmund/herausgegeben von der Gesellschaft für Arbeitswissenschaften e.V., Dortmund: GfA-Press, 2009, pp 101-104. ISBN 978-3-936804-07-9

Stüdeli T, Kalkofen D, Freudenthal A (2007) How do interventionists navigate to the tumour? In: Berlin C, Bligård LO (eds) Proceedings of the 39th Nordic Ergonomics Society Conference, 1-3 Oct 2007, Lysekil, Sweden. ISBN 978-91-971521-2-9, Online available: http://www.nes2007.se/papers/A117_Studeli.pdf 